has produced an agreement on three plans for the assignment of frequencies to European broadcasting (including television) within the three bands 41-68, 87.5-100 and 174-216 Mc./s. 'The General Post Office, which is the responsible administration in Great Britain, has stated that the Conference accepted the assignments which the United Kingdom has made for the five high-power and five low-power television stations being established by the B.B.C. For the second band $(87.5-100 \mathrm{Mc} . / \mathrm{s}$.) the British delegation was successful in securing alternative sets of frequencies for amplitude and for frequency modulation, respectively. The agreement was signed on behalf of the administrations of twenty-one of the thirty-one countries represented at the Conference.

\section{Anatomical Nomenclature}

AN international meeting of anatomists was recently held in London to discuss a proposal to establish an agreed anatomical nomenclature. 'The first attempt. to reach a similar agreement was the work of a small committee, predominantly German in constitution, which was convened by the German Anatomical Society at its Leipzig meeting in 1887. This committee devised a list of terms, now known as the BNA, which was adopted at a meeting in Basle in 1895 . The BNA has been endorsed by a number of countries; but nevertheless is not an internationally approved scheme. In 1933 the Anatomical Society of Great hritain and Ireland approved an English revision, and a German revision was published in 1936. The recent London meeting agreed that any new international nomenclature should be based on the BNA, which it was hoped would require a minimum of change. It was also agreed that each country was at liberty to translate the official Latin terms of the BNA into its own vernacular for teaching purposes; but that, wherever possible, official Latin terms should be used in publications. 'The revision of the BNA is the responsibility of professional anatomists ; but it was decided that it would be in the best interests of all if physiologists, pathologists, clinicians, and others concerned in the education of medical students, should communicate any views they might have about anatomical nomenclature to the committee. According to a recent letter to The Lancet (July 5, 1952), Prof. T. B. Johnston (Guy's Hospital, London, S.F.1) is undertaking the task of collating such proposals in Great Britain. The various sub-committees dealing with this matter hope to submit a report to the International Congress of Anatomists to be held in France in 1955 .

\section{History of Science}

LAST year the attention of readers of Nature was directed to the publication, by E. Munksgaard, of Copenhagen, of the first two numbers of Centaurus, a new quarterly devoted to the history of science and medicine (Nature, 167, 841). Three further numbers have since appeared, containing fifteen original articles on a variety of subjects of scientific, medical, biographical and bibliographical interest. Among these may be noted, in Vol. 1, No. 3, a critical article by Prof. Benjamin Farrington on Francis Bacon's "Temporis Partus Masculus", and, in the first number of Vol. 2, Prof. Edward Rosen, of New York, discusses when Galileo made his first telescope. Under the heading "Varia", in Vol. 1, No. 4, is a description of the recently established Belgian Museum for the History of Science, situated in Ghent. First planned in 1939 , war delayed its opening until 1948. It was first housed in the Archæological Museum, but latterly was moved to more spacious accommodation in the Museum of Fine Arts. The Museum is stated to be especially rich in old medical and surgical instruments, a new acquisition being a collection of surgical instruments representative of ancient Egypt and the Middle East. Documents, both printed and manuscript, bearing on the history of the sciences also form part of the collections. Each number of Centaurus contains several book reviews and there are also extensive lists of books received. The high standard of printing and illustration is maintained, and this quarterly is one well worth the attention of British readers interested in the history of science and medicine.

\section{Gamma-Ray Sources for Radiography}

A COMMTTTEE of the Industrial Radiology Group of the Institute of Physics has recently prepared a "Memorandum on Gamma-Ray Sources for Radiography" (obtainable from the Institute; pp. 23 ; $1952 ; 3 s .6 d$.$) , which provides a brief statement of$ the physical characteristics of the gamma-ray sources for radiography by means of which a wide range of radiography can be carried out without X-ray equipment. In addition to the older, costly and somewhat rare, radium there are now available sources consisting of radon obtainable from the Radiochemical Centre, Amersham, and three artificial radioactive sources cobalt-60, tantalum-182 and iridium-192from the Atomic Energy Research Establishment, Harwell. Attention is directed in the memorandum to radiographic technique, protection of personnel and precautions to be taken when handling or transporting the sources, and to the cost of installation of the necessary equipment for gamma-radiography. Useful data sheets, summarizing essential information and obtainable from official sources, are included as an appendix to the memorandum. For example, cobalt-60, which has a half-life of $5 \cdot 3$ years and is recommended for the radiography of steel 2-6 in. thick, costs $£ 40$ approximately for the equivalent of $1 \mathrm{gm}$. of radium; the radium can be supplied on loan at a rental of $£ 225$ a year. The activity of radium remains sensibly constant with time whereas that of the other sources decreases; but the artificial sources can be returned to the atomic pile for reactivation. With regard to the technique of gamma-radiography, it is mentioned that the technique is simpler than that using X-rays, but the interpretation of the results is a skilled job. Though the radiographer must have an adequate knowledge of protection and must be a responsible person, his training need not be so broad in scope as that for X-radiography, since no highvoltage circuits are involved. Training facilities, though limited, are available in Great Britain, and particulars of these can be obtained from the Institute of Physics, 47 Belgrave Square, London, S.W.1.

\section{Twenty Years of Work at the Jungfraujoch}

THE November 1951 issue of $L$ 'Astronomie contains a number of interesting articles, two of which are connected with the scientific station of Jungfraujoch, and are contributed by M. D. Chalonge, director of the station. The first of these refers to the celebration of the twentieth anniversary of the inauguration of the station in 1931, which took place on September 26 and 27,1951 , at Interlaken and afterwards at the Jungfraujoch itself. A short account is given of the 